Thực hành VSRM của hoc sinh ở mức trung bình, đạt 5,00 điểm. Tỉ lệ học sinh thực hành tốt chiếm $3,10 \%$, khá chiếm $12,40 \%$, trung bình chiếm $59,69 \%$, kém chiếm 24,81\%.

Học sinh nữ có kiến thức, thái độ, thực hành VSRM tốt hơn học sinh nam.

\section{TÀI LIÊU THAM KHẢO}

1. Trịnh Đình Hải. Báo cáo tóm tắt kết quả điều tra chương trình chăm sóc sức khỏe răng miệng ở học sinh tiểu học tại Việt Nam năm 2011. Hội nghị Châu A-Thái Bình Dương lần thứ 6 về sức khỏe răng miệng cho học sinh các trường phổ thông năm 2011 tai Viêt Nam;96.

2. Trương Mạnh Dũng, Ngô Văn Toàn. Nha cộng đồng tâp 1. In: Nhà xuất bản Y học; 2013:160.

3. Lưu Ngọc Hoạt. Phương pháp nghiên cứu sức khỏe cộng đồng. In: Nhà xuất bản $Y$ học; 2013:188.

4. Trân Thị Mỹ Hạnh, Hà Ngọc Chiều, Phùng Thi Thu Hà, Tống Minh Sơn, Võ Trương Như
Ngọc. Kiễn thức, thái độ, hành vi của học sinh trường tiểu hoc Thanh Liêt về chăm sóc răng miệng. Tạp chí Y học thực hành. 2014;(4): 57-60.

5. Vũ̃ Thị Sao Chi, Nguyê̂n Thị Trang Nhung, Thẩm Chí Dũng. Thực trang sâu răng, viêm lợi và một số yếu tố liên quan ở học sinh trường Trung hợ cơ sở Tân Bình, thành phố Hải Dương năm 2015. Hội nghị khoa học-công nghệ tuổi trẻ các trường đại học, cao đẳng Y-dược Việt Nam lần thứ XVIII, 2016.

6. Bùi Thị Thu Hiên, Lê Long Nghĩa, Đinh Xuân Thành. Kiến thức, thái độ, thức hành chăm sóc răng miệng của học sinh tại Trường Trung học cơ sở Bông Sơn, huyện Hoài Nhơn, tỉnh Bình Định năm 2019. Tạp chí y dược lâm sàng 108. 2020;(7):15.

7. Nguyển Ngọc Nghĩa, Kiến thức, thái độ và thực hành của học sinh tiểu học trong chăm sóc sức khỏe răng miệng tai huyện Văn Chấn-tỉnh Yên Bái, năm 2009. Luận vằn thạc sĩ Y học, trường Đại học Y Dược Thái Nguyên.

\title{
GÁNH NẶNG NHIÊTT CỦA NHÂN VIÊN Y TẾ VÀ CÁN Bộ PHÒNG CHỐNG DỊCH TRONG TRANG PHỤC PHÒNG DİCH
}

\author{
Nguyễn Thu Hà*, Trần Văn Toàn*, Nguyễn Đức Sơn*
}

\section{TÓM TẮT}

Mục tiêu: Đánh giá gánh nặng nhiệt của nhân viên y tế và cán bộ phòng chống dịch trong trang phục phòng dịch. Đối tượng và phương pháp: 30 nhẩn viên làm việc với trang phục quần áo phòng dịch trong 4 giờ liên tục được ghi liên tục nhiệt độ bên trong và ngoài bộ quần áo phòng dịch bằng gắn Dataloger; đo nhiêt độ trung tâm, nhiêt đô da, khối lượng mồ hôi, (trước - sau khi làm việc) và phỏng vấn cảm giác nhiệt. Kết quả: - 97,1\% thời gian nhiệt độ bên trong cao hơn nhiệt độ bên ngoài bộ quần áo phòng dịch từ $0,5^{\circ} \mathrm{C}$ đên $4,5^{\circ} \mathrm{C}$. - Có sự tăng nhiệt độ da, nhiête độ dưới lưỡi, khối lượng mồ hôi ở nhân viên làm việc trong trang phục quần áo phòng dịch $(p<0,05-p<0,001)$ sau lao động so với trước lao động. - Cảm giác "nóng" và "rất nóng"; cơ thể ở mức "rất khó chiu" và "không thể chiu đựng nổi" tăng dần theo từng giờ, tỷ lệ thuận với thời gian mặc quân áo phòng dịch. 93,4\% có cảm giác "nóng" và "rất nóng"; một nhân viên phải dừng thử nghiệm và phải xử lý vấn đề về sức khỏe. Kết luận: Mặc quần áo phòng dịch khi làm việc ảnh hưởng bất lợi tới sức khỏe.

Từ khóa: Gánh nặng nhiệt, quần áo phòng dịch, nhân viên y tế, cán bộ phòng chống dịch

\footnotetext{
*Viện Sức khỏe nghề nghiệp và Môi trường

Chịu trách nhiệm chính: Nguyễn Thu Hà

Email: thuhayhld@gmail.com

Ngày nhận bài: 7.6.2021

Ngày phản biên khoa họ: 30.7.2021

Ngày duyệt bài: 9.8.2021
}

\section{SUMMARY \\ HEAT STRESS OF HEALTH CARE WORKER AND EPIDEMIC PREVENTION STAFFS IN PERSONAL EPIDEMIC PREVENTION CLOTHES}

Objective: To evaluate the heat stress of health care worker and epidemic prevention staffs in personal epidemic prevention clothes. Objects and methods: 30 staff working with epidemic prevention clothing for 4 hours continuously recorded the temperature inside and outside the epidemic prevention clothes by attaching Dataloger; measure core temperature, skin temperature, sweat (before - after working) and heat feeling interview. Result: $-97.1 \%$ of the time the inside temperature is higher than the outside temperature of the epidemic prevention clothes from $0.5^{\circ} \mathrm{C}$ to $4.5^{\circ} \mathrm{C}$; -Increasing the skin temperature, under the tongue temperature, sweat in staff working in protective clothing after work compared to before work $(p<0.05-p<0.001)$. -Feelings of "hot" and "very hot"; the body's level of "very uncomfortable" and "unbearable" increases every hour, proportional to the time it takes to wear protective clothing. 93.4\% feel "hot" and "very hot"; one staff must stop the test and health treatment. Conclusion: Working with epidemic prevention clothing is harmful effects on health

Keywords: Heat stress, epidemic prevention clothes, health care worker, epidemic prevention staffs

\section{I. ĐẶT VẤN ĐỀ}

Đại dịch Covid 19 diễn ra từ năm 2019 tới thời điểm hiện tại không những gây ra hậu quả nặng nề về sức khỏe và tính mạng con người 
mà còn ảnh hưởng trực tiếp đến sức khỏe những nhân viên y tế, cán bộ phòng chống dịch. Nhân viên y tế, cán bộ tham gia phòng chống dịch là những người tiếp xúc trực tiếp với các bệnh nhân nhiễm virus SARS-CoV-2 hoặc tiếp xúc với các người có nguy cơ lây nhiễm, họ còn phải chịu đựng sự nóng bức, khó chịu trong những bộ quần áo và khẩu trang phòng chống dịch ở điều kiện nắng nóng của thời tiết nhiệt đới, đặc biệt là trong mùa hè.

Do hệ số dẫn nhiệt của vật liệu làm quần áo chống dịch là rất nhỏ, nên khả năng trao đổi nhiệt của bộ quần áo này là rất thấp, không khí bên trong bộ quần áo chống dịch hầu như không di chuyển và liên thông với bên ngoài, đồng thời nó ngăn cản quá trình bốc hơi mồ hôi làm ảnh hưởng đến sự giảm nhiệt bề mặt da mà chuyển động khí đối lưu trên ra và bốc hơi mồ hôi trên bề mặt ra là hai con đường chính để trao đổi nhiệt giữa cơ thể với môi trường bên ngoài [4]. Cộng thêm stress khi tiếp xúc trực tiếp với bệnh nhân càng làm tăng quá trình sinh nhiệt, kết quả là người mặc bộ đồ chống dịch làm việc trong điều kiện nhiệt độ cao của môi trường nắng nóng ẩm thấp, nhiệt độ bề mặt da sẽ tăng cao hơn so với bình thường, dẫn đến tăng thân nhiệt và cảm giác nóng bức khó chịu. Thời gian mặc càng lâu cảm giác này càng nặng nề hơn, có thể dẫn đến hiện tượng ngất xỉu so say nóng.

Trên thế giới nói chung và tại Việt Nam nói riêng đã có nhiều trường hợp nhân viên y tế bị kiệt sức, ngất xỉu và thậm chí có nguy cơ tử vong khi đang làm nhiệm vụ phòng chống dịch. Vào ngày $12 / 5 / 2021$, ngày $22 / 5 / 2021$, ngày 26/5/2021 nhiêu nữ điều dưỡng, nhân viên y tế, sinh viên tình nguyện đã bị kiệt sức ngất xỉu khi đang lấy mẫu cho nhân dân trong vùng dịch tại tỉnh Bắc Ninh, Bắc Giang... Làm việc liên tục căng thẳng nhiều giờ trong điều kiện nắng nóng trong bộ đồ phòng chống dịch có nguy cơ bị say nóng và say nắng (stress nhiệt và shock nhiệt).

Chính vì vậy việc đánh giá gánh nặng nhiệt và gánh nặng thể lực của nhân viên y tế và cán bộ phòng chống dịch trong trang phục phòng dịch là rất cần thiết, từ đó là cơ sở để có các đề xuất giải pháp giảm thiểu ảnh hưởng đến sức khỏe nhân viên y tế và cán bộ phòng chống dịch.

Mục tiêu nghiên cứu: Đánh giá gánh năng nhiệt và gánh nặng thể lực của nhân viên y tế và cán bộ phòng chông dịch trong trang phục phòng dịch

\section{II. ĐỐI TƯỢNG VÀ PHƯƠNG PHÁP NGHIÊN CỨU \\ 2.1. Đối tượng nghiên cứu: 30 nhân viên}

mặc quần áo chống dịch, bao gồm:

- Nhân viên làm việc ngoài trời: thực hiện các cônng việc đo nhiệt độ cơ thể, sát khuẩn, hướng dẫn khai báo y tế...

- Nhân viên làm việc trong phòng xét nghiệm: thực hiện các công việc xử lý mẩu, phân tích mẩu trong phòng xét nghiệm...

- Thời gian mặc quần áo chống dịch 4 giờ liên tục

\subsection{Phương pháp nghiên cứu}

2.2.1. Thiết kế nghiên cứu: Nghiên cứu thực nghiệm, mô tả cắt ngang

2.2.2. Phương pháp chọn mẫu: Chọn mẫu chủ đích

2.2.3. Thời gian nghiên cứu: tháng 5 năm 2021

2.2.4. Các chỉ số nghiên cứu và kỹ thuật

- Đánh giá chỉ số gánh nặng nhiệt (Heat Index - HI): gắn dataloger (bển trong và bên ngoài quần áo chống dịch) trong suốt quá trình nhân viên mặc quần áo chống dịch. Các số liệu được ghi liên tục 5 phút/lần.

Phân loại gánh nặng nhiệt (theo NOAA - Mỹ)

\begin{tabular}{|c|c|c|}
\hline Mức & Chỉ số HI & $\begin{array}{c}\text { Phân loại gánh } \\
\text { nặng nhiệt }\end{array}$ \\
\hline 0 & $<27$ & Không \\
\hline 1 & $27-32$ & Cảnh báo \\
\hline 2 & $33-40$ & Đặc biệt cảnh báo \\
\hline 3 & $41-53$ & Nguy hiếm \\
\hline 4 & $\geq 54$ & Rất nguy hiếm \\
\hline
\end{tabular}

- Đo Nhiệt độ da: phương pháp đo 3 điểm, tính nhiệt độ da trung bình theo công thức của Burton (đã hiệu chỉnh theo diện tích da của người Việt Nam): $\mathrm{T}^{\circ}{ }_{\text {da }} \mathrm{TB}=0,42 \mathrm{~T}^{\circ}{ }_{\text {ngực }}+0,39$ $\mathrm{T}^{\mathrm{O}}$ cẳng chân $+0,19 \mathrm{~T}^{0}$ cẳng tay

- Đo nhiệt độ trung tâm: đo nhiệt độ dưới lưỡi

- Đo khối lượng mồ hôi: đối tượng được lau khô mồ hôi, không mặc quần áo khi cân. Tính lượng mồ hôi mất đi sau mối giờ

- Phỏng vấn cảm giác nhiệt (1 giờ 1 lần) theo mẫu phiếu bằng quét mã $\mathrm{QR}$

2.3. Y đức trong hoạt động nghiên cứu: Tuân thủ các quy định về đạo đức trong nghiên cứu.

\subsection{Phương pháp xử lý số liệu:}

- Sử dụng các phần mềm chuyển dụng trong phân tích các số liệu chuyên sâu: phần mềm phân tích dataloger

- Sử dụng các thuật toán thống kê $Y$ học thích hợp (phương pháp so sánh cặp, test $t$, VV...) và chương trình SPSS 25.0 để xử lý, phân tích số liệu

\section{KẾT QUẢ NGHIÊN CỨU}

3.1. Chỉ số gánh nặng nhiệt HI. $97,1 \%$ thời gian nhiệt độ bên trong cao hơn nhiệt độ bên ngoài bộ quần áo phòng dịch từ $0,5^{\circ} \mathrm{C}$ đến 
$4,5^{\circ} \mathrm{C}$ khi ghi liên tục nhiệt độ bên trong và ngoài bộ quần áo phòng dịch bằng gắn Dataloger ở toàn bộ nhóm nghiên cứu.

Bảng 1. Chỉ số gánh nặng nhiêtt trong quần áo chống dịch (HI) (nhóm làm việc ngoài trời)

\begin{tabular}{|c|c|c|c|}
\hline $\begin{array}{c}\text { Chỉ số gánh nă̆ng } \\
\text { nhiệt trong quần áo } \\
\text { chống dịch (HI) }\end{array}$ & $\mathbf{n}$ & $\%$ & $\begin{array}{c}\text { Thời } \\
\text { gian } \\
\mathbf{( \% )}\end{array}$ \\
\hline Mức 3: Nguy hiếm & 1 & 6,7 & 58,54 \\
\hline Mức 4: Rất nguy hiểm & 14 & 93,3 & $\begin{array}{c}31,58- \\
87,8\end{array}$ \\
\hline
\end{tabular}

Nhóm nhân viên làm việc ngoài trời phải chịu mức HI chủ yếu ở mức 3 (mức nguy hiểm) hoặc mức 4 (mức rất nguy hiểm). 93,3\% nhân viên có chỉ số HI khi mặc quần áo chống dịch có mức $\mathrm{HI}$ ở mức 4 (mức rất nguy hiểm) với thời gian là $31,58 \%-87,8 \%$ thời gian ca lao động và ở mức 3 (mức nguy hiểm) là $6,7 \%$ với thời gian là $58,54 \%$ thời gian ca lao động.

Bảng 2. Chỉ số gánh nặng nhiêt trong quần áo chống dịch (HI) (nhóm làm việc trong phòng xét nghiệm)

\begin{tabular}{|c|c|c|c|}
\hline $\begin{array}{c}\text { Chî số gánh nắng } \\
\text { nhiệt trong quần áo } \\
\text { chống dịch (HI) }\end{array}$ & $\mathbf{n}$ & $\%$ & $\begin{array}{c}\text { Thời } \\
\text { gian } \\
\text { (\%) }\end{array}$ \\
\hline Mức 1: Cảnh báo & 1 & 6,7 & $47,5 \%$ \\
\hline Mức 2: Đắc biệt cảnh & 6 & 40,0 & $\begin{array}{c}50- \\
\text { báo }\end{array}$ \\
\hline Mức 3: Nguy hiểm & 8 & 53,3 & $\begin{array}{c}76,32- \\
89,47\end{array}$ \\
\hline
\end{tabular}

Nhóm nhân viên làm việc trong phòng xét nghiệm chịu mức HI chủ yếu ở mức 2 (đăc biệt cảnh báo) hoặc mức 3 (mức nguy hiểm). 53,3\% nhân viên có chỉ số HI khi mặc quần áo chống dịch có mức $\mathrm{HI}$ ở mức 3 (mức nguy hiểm) với thời gian là 76,32-89,47\% thời gian ca lao động và ở mức mức 2 (đặc biệt cảnh báo) là $40,0 \%$ với thời gian là $50-92,86 \%$ thời gian ca lao động.

\subsection{Nhiêt đô da}

Bảng 3. Biến đổi nhiệt độ da trung bình (nhóm làm việc ngoài trời)

\begin{tabular}{|c|c|c|}
\hline Nhiệt độ da trung bình & ${ }^{0} \mathbf{C}$ & p \\
\hline $\begin{array}{c}\text { Trước khi mặc quần áo } \\
\text { chống dịch }\end{array}$ & $32,4 \pm 1,86$ & \multirow{2}{*}{$<0,02$} \\
\cline { 1 - 2 } $\begin{array}{c}\text { Sau khi mặc quần áo } \\
\text { chống dịch }\end{array}$ & $33,6 \pm 2,45$ & \\
\hline
\end{tabular}

Khi làm việc có mặc quân áo chống dịch, nhiệt độ da trung bình của nhân viên sau khi mặc quần áo chống dịch là $33,6 \pm 2,45^{\circ} \mathrm{C}$, cao hớn trước khi mặc quần áo chống dịch $\left(32,4 \pm 1,86^{\circ} \mathrm{C}\right)$ có ý nghĩa thống kê $(p<0,02)$ ở nhóm làm việc ngoài trời.

Bảng 4. Biến đổi nhiệt độ da trung bình

(nhóm làm việc trong phòng xét nghiệm)
\begin{tabular}{|c|c|c|}
\hline Nhiệt độ da trung bình & ${ }^{0} \mathbf{C}$ & $\mathbf{p}$ \\
\hline $\begin{array}{c}\text { Trước khi mặc quần áo } \\
\text { chống dịch }\end{array}$ & $32,5 \pm 0,45$ & $<0$ \\
\hline $\begin{array}{c}\text { Sau khi mặc quần áo } \\
\text { chống dịch }\end{array}$ & $33,2 \pm 0,42$ & 001 \\
\hline
\end{tabular}

Khi làm việc có mặc quần áo chống dịch, nhiệt độ da trung bình của nhân viên sau khi mặc quần áo chống dịch là $33,2 \pm 0,42{ }^{\circ} \mathrm{C}$, cao hớn trước khi mặc quần áo chống dịch $\left(32,5 \pm 0,45^{\circ} \mathrm{C}\right)$ có ý nghĩa thống kê $(p<0,001)$ ở nhóm làm việc trong phòng xét nghiệm.

\subsection{Nhiệt độ trung tâm}

Bảng 5. Biến đổi nhiệt độ dưới lưỡi (nhóm làm việc ngoài trời)

\begin{tabular}{|c|c|c|}
\hline Nhiệt độ dưới lưỡi & ${ }^{0} \mathbf{C}$ & p \\
\hline $\begin{array}{c}\text { Trước khi mặc quần } \\
\text { áo chống dịch }\end{array}$ & $37,2 \pm 0,24$ & \multirow{2}{*}{$<0,001$} \\
\hline $\begin{array}{c}\text { Sau khi mặc quần áo } \\
\text { chống dịch }\end{array}$ & $37,5 \pm 0,25$ & \\
\hline
\end{tabular}

Khi làm việc có mặc quần áo chống dịch, nhiệt độ dưới lưỡi của nhân viên sau khi mặc quần áo chống dịch là $37,2 \pm 0,24^{\circ} \mathrm{C}$ cao hớn trước khi mặc quần áo chống dịch $\left(37,5 \pm 0,25^{\circ} \mathrm{C}\right)$ có ý nghĩa thống kê $(p<0,001)$ ở nhóm làm việc ngoài trời.

Bảng 6. Biến đổi nhiệt độ dưới lưỡi (nhóm làm việc trong phòng xét nghiệm)

\begin{tabular}{|c|c|c|}
\hline Nhiết độ dưới lưỡi & ${ }^{\mathbf{0}} \mathbf{C}$ & $\mathbf{p}$ \\
\hline $\begin{array}{c}\text { Trước khi mặc quần áo } \\
\text { chống dịch }\end{array}$ & $36,8 \pm 0,34$ & \multirow{2}{*}{$<0,01$} \\
\hline $\begin{array}{c}\text { Sau khi mă̆c quần áo } \\
\text { chống dịch }\end{array}$ & $37,0 \pm 0,30$ & \\
\hline
\end{tabular}

Khi làm việc có mặc quần áo chống dịch, nhiệt độ dưới lưỡi của nhân viên sau khi mặc quần áo chống dịch là $37,0 \pm 0,30^{\circ} \mathrm{C}$ cao hớn trước khi mặc quần áo chống dịch $\left(36,8 \pm 0,34^{\circ} \mathrm{C}\right)$ có ý nghĩa thống kê $(p<0,01)$ ở nhóm làm việc trong phòng xét nghiệm

\subsection{Khối lượng mồ hôi}

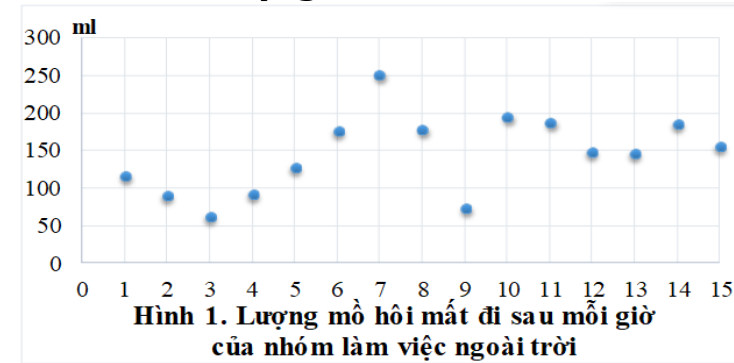

Lượng mồ hôi mất đi sau mỗi giờ làm việc của nhân viên ở nhóm làm việc ngoài trời cao nhất là $251 \mathrm{ml}$ (1nhân viên), còn lại nằm trong khoảng $62-195 \mathrm{ml}$ 


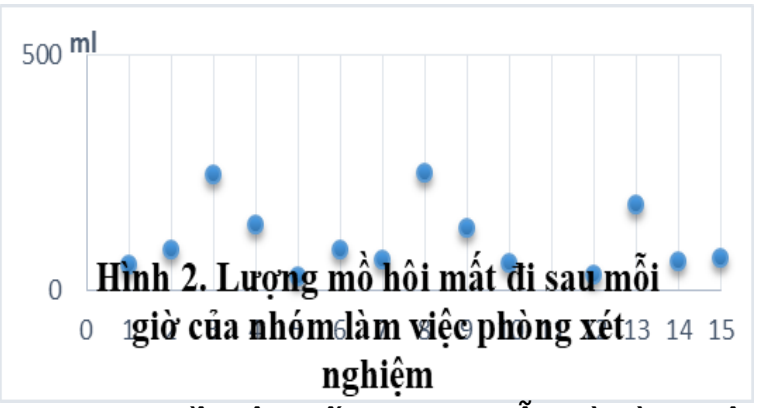

Lượng mồ hôi mất đi sau mỗi giờ làm việc của nhân viên ở nhóm làm việc trong phòng xét nghiệm có 2 nhân viên mất: $245 \mathrm{ml}$ và $247 \mathrm{ml}$, còn lại nằm trong khoảng $27-179 \mathrm{ml}$.

3.5. Cảm giác nhiệt. Nhân viên sau khi mặc trang phục chống dịch cảm giác và trạng thái thay đổi theo thời gian, đặc biệt là cảm giác nóng và trang thái khó chịu: Cảm giác "nóng" và "rất nóng"; cơ thể ở mức "rất khó chịu" và "không thể chịu đựng nổi" tăng dần theo từng giờ, tỳ lệ thuận với thời gian mặc quần áo phòng dịch. $93,4 \%$ có cảm giác "nóng" và "rất nóng"; một nhân viên phải dừng thử nghiệm và phải xử lý vấn đề về sức khỏe.

Nhóm làm việc ngoài trời: Ở thời điểm sau khi mặc quần áo chống dịch được 1 giờ có $46,7 \%$ cảm thây "nóng"; sau 2 giờ là $73,3 \%$; sau 3 giờ là $86,7 \%$. Cảm giác "rất nóng" chưa xuất hiện sau mặc quần áo chống dịch sau 1 giờ; sau 2 giờ và 3 giờ tỷ lệ này là $6,7 \%$ và ở cuối buổi có tới $25,7 \%$ có cảm giác "rất nóng". ở thời điểm sau khi mặc quần áo chống dịch được 1 giờ có $26,7 \%$ cảm thấy "khó chịu", sau 2 giờ tỷ lệ cảm thấy "khó chịu" tăng lên là $86,7 \%$. Sau 1 giờ, 2 giờ cảm thây "rất khó chịu" là $6,7 \%$; sau 3 giờ trạng thái này tăng lên là $20 \%$, chưa xuất hiện cảm giác "cực kỳ khó chịu". Và ở cuối buổi có 6,7\% có trạng thái "cực kỳ khó chịu".

Nhóm làm việc phòng xét nghiệm: ở thời điểm sau khi mặc quần áo chông dịch được 1 giờ, 2 giờ chưa có cảm thấy "hơi nóng"; sau 3 giờ 20,0\% xuất hiện cảm giác "hơi nóng"; sau 4 giờ là $13,3 \%$ "hơi nóng" và $6,7 \%$ là "nóng". Ở thời điểm sau khi mặc quần áo chống dịch được 1 giờ có $6,7 \%$ cảm thấy "khó chịu", sau 2 giờ tỷ lệ cảm thấy "khó chịu" tăng lên là 33,3\%; sau 3 giờ là $53,3 \%$; chưa xuất hiện cảm giác "rất khó chịu". Và ở cuối buổi có $13,3 \%$ có trạng thái "rất khó chịu".

\section{BÀN LUÂNN}

Các con đường chính để mất nhiệt trao đổi chất là thông qua chuyển động không khí đối lưu trên da và bốc hơi mồ hôi trên bề mặt da [4].
Khi cán bộ, nhân viên y tế khoác trên mình quần áo chống dịch với chất liệu dẫn nhiệt kém không thể lưu thông không khí và truyền tải nhiệt giữa 2 bên của lớp quần áo chống dịch dẫn đến nhiệt độ ở khoảng giữa quần áo chống dịch với cơ thể bị tăng lên, cụ thể trong nghiên cứu của chúng tồi đã cho thấy rằng sự chênh lệch này là có và cao nhất tới 4,50 $\mathrm{C}$. Qua bảng $3,4,5,6$ chúng ta có thể thấy rằng nhiệt độ trung tâm và nhiệt độ bề mặt da sau khi mặc quần áo chống dịch luôn cao hởn so với thời điểm trước khi mặc do chính sự giảm lưu thông không khí đã làm giảm quá trình trao đổi nhiệt giữa cơ thể với môi trường ngoài: khi nhiệt độ da, nhiệt độ trung tâm trước mặc luôn thấp hơn và sự lưu thông không khí trước mặc luôn tốt hơn lúc vừa làm việc vừa mặc quần áo chống dịch.

Trong quá trình làm việc của các cán bộ, nhân viên y tế còn sử dụng thêm các trang bị phòng hộ khác: kính, khẩu trang, găng tay... Các trang bị này 1 phần gây khó chịu cho cán bộ, nhân viên trong quá trình làm việc: cản trở hô hấp, tăng nhiệt độ da trên bề mặt [2] [3]...Theo Cotter JD và cộng sự năm 2005 da mặt là một trong những nơi nhạy cảm với nhiệt độ cao nhất và cảm giác khó chịu trên cơ thể con người [1] cộng thêm với sự tăng nhiệt độ trung tâm, nhiệt độ bề mặt da, nhiệt độ môi trường xung quang cơ thể, giảm thông thoáng gió đã làm cán bộ, nhân viên cảm thây khó chịu, nóng... trong quá trình làm việc với trang phục chống dịch. Cảm giác, trang thái này thay đổi theo thời gian làm việc: sau 1 giờ làm việc cảm giác nóng là $46,7 \%$, và đạt tới $86,7 \%$ sau 3 giờ làm việc (nhóm làm việc ngoài trời) đồng thời xuất hiện cảm giác rất nóng 25,7\%; ở nhóm làm việc trong phòng thí nghiệm sau khi mặc 1 giờ chưa có biểu hiện gì nhiểu nhưng đến cuối $6,7 \%$ cảm thấy nóng và 13,3\% cảm thây rất khó chịu.

\section{KẾT LUÂ̂N}

- Nhân viên y tế và cán bộ phòng chống dịch làm việc trong trang phục phòng dịch có những ảnh hưởng bất lợi đối với sức khỏe.

- Nhiệt độ bển trong bộ quần áo chống dịch luôn tương đương hoặc cao hơn nhiệt độ bên ngoài bộ quần áo chống dịch.

- Có đến $97,1 \%$ thời gian trong tổng số thời gian mặc quần áo chống dịch có nhiệt độ bên trong bộ quần áo chống dịch cao hơn nhiệt độ bên ngoài bộ quần áo chống dịch với nhiệt độ chênh là từ $0,5^{\circ} \mathrm{C}$ đến $4,5^{\circ} \mathrm{C}$ tùy theo tính chất công việc (nhân viên y tế và cán bộ phòng chống dịch đo nhiệt độ cơ thể, sát khuẩn, hướng dẫn 
khai báo y tế... (nhân viên làm việc ngoài trời) hay nhân viên xử lý mẫu, phân tích mẫu trong phòng thí nghiệm... (nhân viên làm việc trong phòng xét nghiệm).

- Sự tăng nhiệt độ bên trong quân áo chống dịch khi mặc so với nhiệt độ bên ngoài của quân áo chống dịch làm tăng thêm gánh nặng thể lực và gánh nặng nhiệt ở nhân viên y tế, cán bộ phòng chống dịch

\section{TÀI LIỆ THAM KHẢO}

1. Cotter J.D. and Taylor N.A.S. (2005). The distribution of cutaneous sudomotor and alliesthesial thermosensitivity in mildly heatstressed humans: an open-loop approach. J Physiol, 565(Pt 1), 335-345.

2. DuBois A.B., Harb Z.F., and Fox S.H. (1990). Thermal discomfort of respiratory protective devices. Am Ind Hyg Assoc J, 51(10), 550-554.

3. Laird I.S., Goldsmith R., Pack R.J. and Vitalis A.. (2002). The effect on heart rate and facial skin temperature of wearing respiratory protection at work. Ann Occup Hyg, 46(2), 143-148.

4.Parsons KC .(2010). Human thermal environments. 2nd edn. London, UK: Taylor \& Francis

\section{TỔNG QUAN VÊ CÁC THANG ĐIỂM LÂM SÀNG TRONG CHẨN ĐOÁN VA QUÁ PHÁT Ở TRẺ EM}

\section{TÓM TẮT}

VA quá phát là bênh lý thường gặp ở trẻ em ước tính khoảng $49,70 \%{ }^{1}$. Chẩn đoán VA quá phát ở trẻ em gặp nhiều khó khăn trong quá trình thăm khám do trẻ không hợp tác. Một số trường hợp phải gây mê để đánh giá tình trang VA và xác định phương án xử trí. Nhiều tác giả đã nghiên cứu các thang điểm lâm sàng đểđánh giá mức độ VA quá phát. Chúng tôi tiến hành nghiên cứu từ tháng 11 năm 2020 đến tháng 6 năm 2021 về tổng quan luận điểmcác tài liệu khoa hoc được xuất bản trên thế giới với mục tiêu: tổng hợp các thang điểm lâm sàng chẩn đoán VA quá phát hiên có và nhận xét kết quảcủa các thang điểm này. Kết quả đạt được: có 10 bài báo toàn văn về thang điểm lâm sàng chẩn đoán VA quá phát đạt tiêu chuẩn. Thang điểmKappa score với độ chính xác là 86,9\%. Các triệu chứng lâm sàng thường gặp nhất là: ngủ ngáy $8 / 10$; sau đó là thở miêng $7 / 10$; ngừng thở khi ngủ $6 / 10$; khó thở khi ngủ 3/10; giọng mũi kín 3/10; triệu chứng ban ngày $3 / 10$; viêm tai giữa tái diễn $2 / 10$; viêm mũi họng tái diên 2/10; chảy mũi thường xuyên 2/10. 7/10 bài báo có thang điểm chiamức độ VA quá phát; $3 / 10$ bài báo chấm điểm triệu chứng lâm sàng. 4 thang điểm có mối tương quan với $X Q$ sọ bên $p<0,05$, 3thang điểm tương quan với nội soi tai mũi họng $\mathrm{p}<0,05,3$ thang điểm đánh gía độ nhạy và đặc hiệu so với nôii soi mũi lần lượt là $22 \%-71 \%$ và $88 \%-100 \%$.

Tư khóa: tổng quan luận điểm, VA quá phát, điểm triệu chứng lâm sàng.

\section{SUMMARY}

\section{SCOPING REVIEW: CLINICAL SYMPTOMS}

\author{
${ }^{1}$ Bênhh viện đa khoa Đức Giang \\ 2Trường Đai hoc Y Hà Nôii \\ Chịu trách nhiệm chính: Nguyễn Thị Phương Loan \\ Email: phuongloan1192@gmail.com \\ Ngày nhận bài: 8.6.2021 \\ Ngày phản biên khoa hoc: 29.7.2021 \\ Ngày duyệt bài: 9.8.2021
}

\section{Nguyễn Thị Phương Loan', Phạm Thị Bích Đào²}

\section{SCORE FOR DIAGNOSIS ADENOID HYPERTROPHY IN CHILDREN}

Adenoid hypertrophy is a common disease in children and with an estimated rate of $49.70 \%$. Diagnosis of adenoid hypertrophy in children faces many difficulties during examination because they scared. In some cases, anesthesia is required to assess the grade of adenoid. Many authors have studied on clinical symptoms score to diagnose adenoid hypertrophy. We conducted a scoping review from researchs in the world until 06/2021 with objectives synthesize the clinical symptoms scores is available and comment on the result of studies. The result show that 15 studies were selected. The common clinical symptoms are: snoring $8 / 10$; mouth breathing $7 / 10$; sleep apnea $6 / 10$; difficulty breathing while sleeping $3 / 10$; hyponasality $3 / 10$; daytime symptoms $3 / 10$; recurrent otitis media $2 / 10$; recurrent nasopharyngitis 2/10; discharge nose 2/10. 5/7 studies had a statistically significant correlation with lateral skull X-ray, 3 studies had a high correlation with nasal enoscopy, 3 studies assessed the sensitivity and specificity as $22 \%-78 \%$ and $88 \%-100 \%$. score.

Keywords: adenoid hypertrophy, clinical symptom

\section{I. ĐĂT VẤN ĐỀ}

VA quá phát là một trong những nguyên nhân chính gây viêm nhiễm tái diễn ở trẻ em trên mức độ cộng đồng và gây nhiều biến chứng toàn thân ảnh hưởng lâu dài tới cả thể chất và tinh thần trẻ. Chẩn đoán VA qúa phát hiện nay sử dụng 3 phương pháp chính là nội soimũi, XQ sọ bên vàđánh giá lâm sàng. Nội soi mũi được coi là tiêu chuẩn vàng tuy nhiên các bác sĩ thường gặp khó khăn do trẻ không hợp tác khi thăm khám. Nghiên cứu của tác giả Torretta² trên 900 bác sĩ tai mũi họng tại Ý cho thấy $64 \%$ phải sử dụng các biện pháp để kiềm chế trẻ, $22 \%$ bác sĩ 